\title{
EVALUASI KOMUNITAS TERUMBU KARANG DI PERAIRAN CAGAR ALAM LAUT KRAKATAU
}

\section{EVALUATION OF CORAL REEF COMUNITIES IN THE KRAKATAU MARINE RESERVE}

\author{
Novriadi ${ }^{1}$, Endang Linirin Widiastuti ${ }^{1}$, Rikha Aryanie Surya ${ }^{2}$ \\ ${ }^{1}$ Jurusan Biologi FMIPA Universitas Lampung \\ ${ }^{2}$ PEH-BKSDA Lampung \\ e-mail :novdewa@gmail.com \\ Jurusan Biologi FMIPA Universitas Lampung \\ J. Prof.Dr. Soemantri Brojonegoro No. 1, Bandar Lampung, Lampung, Indonesia, 35145
}

\begin{abstract}
Abstrak
Cagar Alam Laut Krakatau berada di daerah vulkanik Gunung Anak Krakatu. Aktivitas seismik yang diakibatkan oleh magma chamber Anak Krakatau menyebabkan goncangan pada dasar laut yang memungkinkan bergesernya substrat yang menjadi tempat terumbu karang tumbuh, Selain itu debu vulkanik akan mempengaruhi kalsifikasi dan pertumbuhan karang sehingga karang yang terbentuk akan rapuh dan rentan terhadap pengaruh lingkungan, seperti arus dan goncangan. Tujuan penelitian ini adalah untuk mengetahui kondisi terkini komunitas serta keanekaragaman terumbu karang di Cagar Alam Laut Krakatau. Penelitian dilakukan dari bulan Juli sampai Oktober 2012. Perairan yang menjadi stasiun penelitian adalah perairan Pulau Rakata. Metode manta tow digunakan pada saat survei pendahuluan dan metode Line Intercept Transect (LIT) digunakan dalam pengambilan data terumbu karang. Stasiun penelitian yang berda di perairan Pulau Rakata dibagi menjadi empat titik pengambilan sampel. pada kedalaman 5 meter dengan panjang transek 50 meter searah garis pantai. Hasil pengamatan menunjukkan bahwa dari 27 spesies dalam 7 famili terumbu karang yang ditemukan pada stasiun penelitian kondisinya bervariasi dari baik sekali hingga rusak dengan tingkat tutupan berkisar antara $90,88 \%, 56,54 \%$, dan $38,32 \%$.
\end{abstract}

Kata Kunci: Terumbu Karang, Cagar Alam Laut Krakatau, Line Intercept Transect (LIT)

Abstract

Krakatau Marine Reserve is in the volcanic area of Anak Krakatau. Seismic activity caused by magma chamber of Anak Krakatau cause shocks at the seabed that allows shifting of the substrate where the coral reefs grow, otherwise it will affect the volcanic dust calcification and coral reef growth that will form brittle, and thus will increase coral susceptibility to environmental influences such as seawater current and existing shocks. The purpose of this study was to determine the current condition and diversity of coral reef communities in the Krakatau Marine Reserve, South Lampung. This study was conducted from July to October 2012 at the island of Rakata waters. In the preliminary survey we used manta tow method and for data collecting used Line Intercept Transect method later (LIT). There were four sampling points, at a depth of 5 meters with each point transect length of 50 meters in the parallel direction with the shoreline. There were found 27 species of coral reef belong to seven families. The percentage of coverage of coral reef communities were vary from $90.88 \%, 56.54 \%$, and $38.32 \%$.

Keywords: Coral Reefs, Marine Nature Reserve Krakatau, Line Intercept Transect (LIT)

\section{PENDAHULUAN}

Kepulauan Krakatau terletak di Selat Sunda, yaitu antara Pulau Jawa dan Pulau Sumatera. Luas daratannya sekitar 3.090 ha terdiri dari Pulau Sertung (1.060 ha), Pulau Panjang (310 ha), Pulau Rakata (1.400 ha) dan Gunung Anak Krakatau (320 ha) (BKSDA, 2012). Cagar Alam laut ini merupakan daerah aktivitas vulkanik Gunung
Anak Krakatau. Aktivitas seismik yang diakibatkan oleh magma chamber Gunung Anak Krakatau menyebabkan goncangan-goncangan pada dasar laut yang memungkinkan bergesernya substrat yang menjadi tempat terumbu karang tumbuh 
Terumbu karang merupakan bentuk simbiosis mutualisme antara biota laut dari filum Cnedaria dan alga penghasil kapur (Zooxanthellae) dan membentuk endapan kalsium karbonat $\left(\mathrm{CaCO}_{3}\right)$ sehingga membentuk suatu ekosistem dalam perairan laut (Nybakken, 1992). Pertumbuhan dan penyebaran terumbu karang sangat tergantung pada kondisi lingkungannya. Beberapa faktor yang mempengaruhi kehidupan dan partumbuhan terumbu karang antara lain perairan yang jernih dengan suhu hangat, gerakan gelombang yang besar, memiliki $\mathrm{pH}$ dan salinitas yang sesuai serta sirkulasi yang lancar dan terhindar dari proses sedimentasi (Nybakken, 1988).

Menurut Suharsono (1998), kondisi terumbu karang di perairan Indonesia telah mengalami kerusakan. Terjadinya kerusakan terumbu karang disebabkan oleh faktor alam dan aktivitas manusia.

Perairan Selat Sunda adalah contoh perairan yang sangat dinamis. Pergantian massa air dari Laut Cina Selatan dan Samudra Hindia, serta aktivitas vulkanik (magma chamber) yang terdapat pada dasar laut di kawasan ini, membuat kondisi kawasan tidak dapat menyediakan habitat dasar laut yang stabil bagi pertumbuhan organisme bentik sehingga habitat yang tersedia tidak begitu bervariasi dibandingkan dengan perairan lain di Indonesia.

Karena kondisi perairan yang dinamis oleh banyak faktor inilah maka dianggap perlu adanya penelitian tentang kondisi terkini terumbu karang di perairan Krakatau secara petiodik dan berkelanjutan. Diharapkan hasil penelitian ini dapat digunakan sebagai acuan pengelolaan kwasan perlindungan laut ini khususnya komunitas terumbu karangnya.

\section{BAHAN dan METODE}

Penelitian ini dilakukan dari Bulan Juli sampai dengan Oktober 2012. Lokasi penelitian berada diperairan Pulau Rakata, Kepulauan Krakatau.

Titik sampling ditentukan dengan menggunakan metode manta tow. Dari hasil survei pendahuluan di permukaan selanjutnya ditentukan lokasi tiga titik sampling di Pulau Rakata dengan alat bantu GPS (Global Position System).

Pengambilan data untuk analisis terumbu karang dilakukan dengan menggunakan metode Line Intercept Transect (LIT). Panjang garis transek yang digunakan 50 meter, dibentangkan sejajar garis pantai, pada kedalaman $5 \mathrm{~m}$. Parameter yang diamati adalah panjang tutupan dan keanekaragaman jenis terumbu karang sesuai dengan pedoman yang telah baku dengan metode Life form, dan didokumentasikan. Identifikasi terumbu karang dilakukan hingga tingkat genus (Veron, 2000).

Data yang di dapat kemudian dihitung persentase tutupan terumbu karang dengan menggunakan rumus :

Keterangan :

PC $=$ Persen tutupan

ni $=$ Luas koloni karang

$\mathrm{n}$ = Luas unit terumbu karang

\section{HASIL dan PEMBAHASAN}

Titik pengamatan yang telah diketahui koordinatnya dengan GPS ditunjukkan pada Gambar 1 berikut :

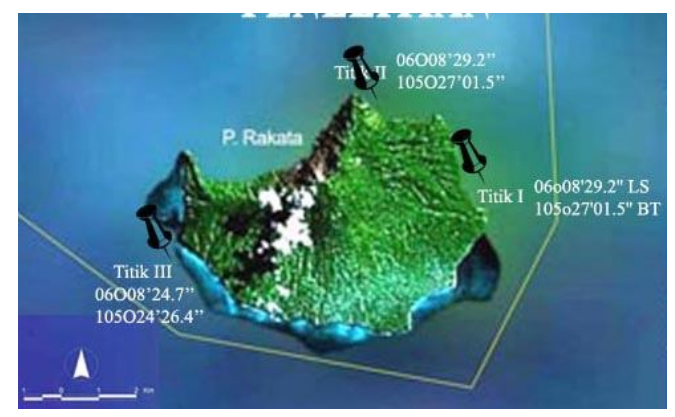

Gambar 1. Titik pengamatan kondisi terumbu karang di Pulau Rakata.

Tutupan terumbu karang hidup pada kedalaman 5 meter di titik sampling I Pulau Rakata memiliki persentase tutupan paling besar, dan di titik titik sampling III Pulau Rakata memiliki persen tutupan paling kecil (Gambar 2).

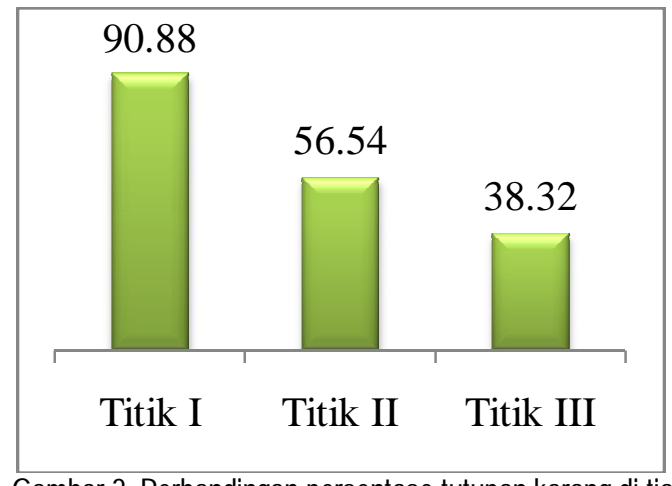

Gambar 2. Perbandingan persentase tutupan karang di tiap titik sampling 


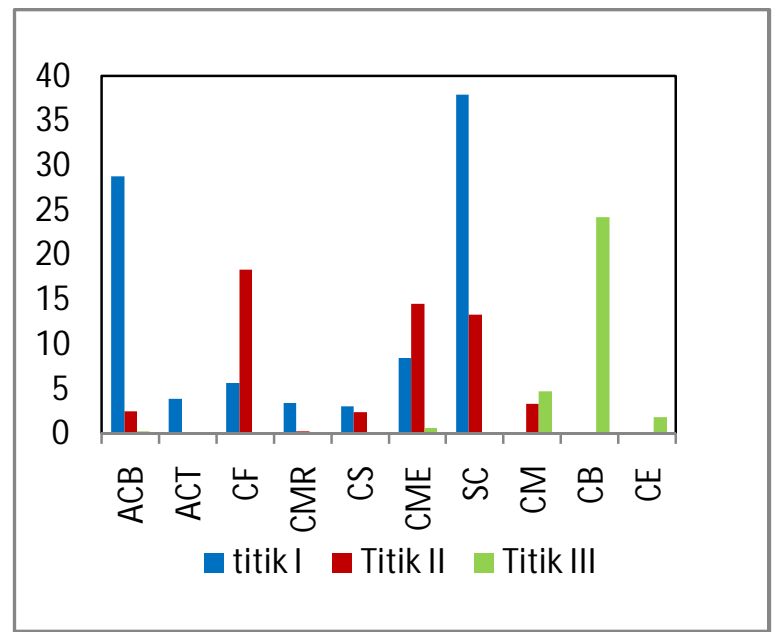

Gambar 3. Perbandingan life form terumbu karang di tiap titik penelitian. (Acropora Branching), ACT (Acropora tabulate), CF (Coral foliose), CMR (Coral mushroom), CS (Coral submassive), CME (Coral millepora), SC (Soft coral), CM (Coral massive), CB (Coral branching), dan CE (Coral encrusting)

Pada titik sampling I terumbu karang didominasi oleh karang lunak dari jenis Xenia sp. dan jenis karang keras, Acropora divaricata dalam bentuk hidup Acropora Branching (ACB). Dilihat dari luas tutupan karang hidupnya, titik ini merupakan daerah yang paling baik di antara titik lain (Gambar 1). Sedangkan titik yang memiliki tutupan terumbu karang paling rendah adalah titik III. Titik ini didominasi oleh jenis Montipora digitata dalam bentuk hidup coral branching atau karang bercabang sebesar $24,20 \%$. Daerah ini hampir seperempatnya adalah pasiran, yang berarti secara alami daerah ini memang tempat yang kurang mendukung untuk pertumbuhan karang dibanding titik lainnya. Selanjutnya titik II Pulau Rakata memiliki persen tutupan karang sebesar $56,54 \%$ yang didominasi oleh jenis Montipora hispida dari bentuk hidup Coral Foliose (Gambar 4).

Kondisi perairan di Cagar Alam Laut Krakatau sangat dinamis dan selalu berubah-ubah. Perairan ini sangat dipengaruhi oleh pola arus yang sangat khas berkaitan dengan tiupan angin. Penelitian yang dilakukan bertepatan dengan musim angin timur sehingga arus yang sangat menonjol berasal dari arah selatan dan timur. Titik sampling II di Pulau Rakata terletak berhadapan langsung dengan Gunung Anak Krakatau. Sedangkan titik I dan III berada di Pulau Rakata yang sedikit menjauhi Gunung Anak Krakatau dengan posisi titik I berada di timur Rakata dan titik III di barat Rakata. Namun dari posisi letak titik sampling tesebut menghasilkan karakter kondisi karang yang berbeda-beda.

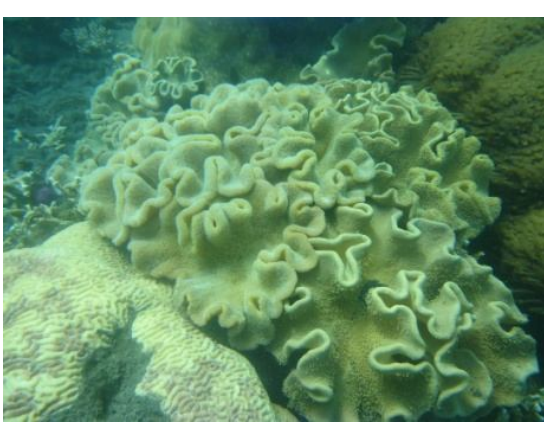

Titik 1

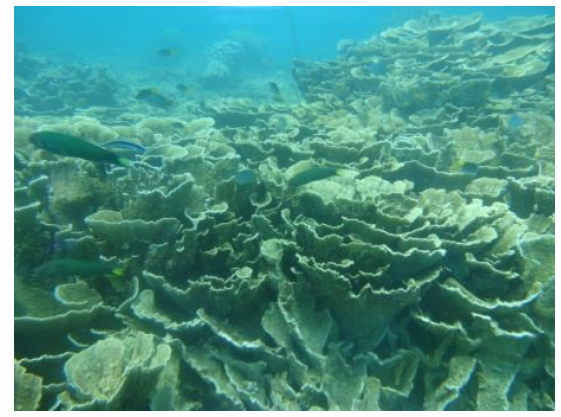

Titik 2

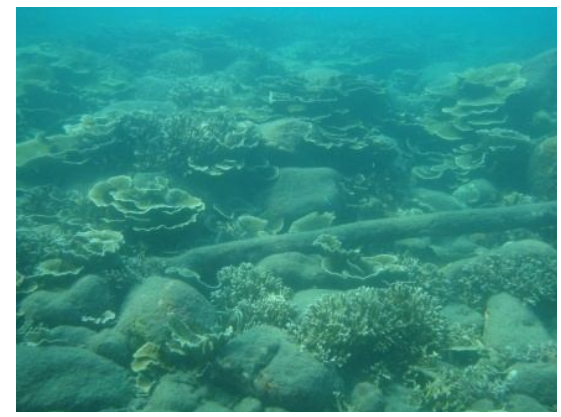

Titik 3

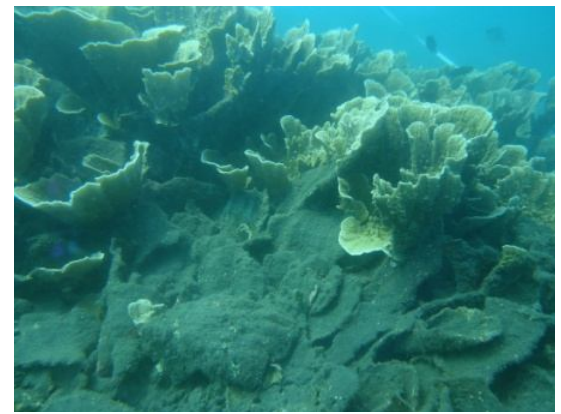

Titik 3

Gambar 4. Kondisi terumbu karang di masing-masing titik penelitian perairan Pulau Rakata

Perairan Krakatau memiliki pola arus yang dipengaruhi oleh arus dari Samudera Hindia (angin selatan) dan Laut Jawa (angin utara). Hal ini 
mempengaruhi pola pertumbuhan karang yang terlihat jelas pada titik III yang berhadapan dengan Samudera Hindia. Kondisi perairan di titik ini memiliki karakter yang di dominasi oleh batuan dan arus yang terlampau tinggi sehingga diduga planula terumbu karang sulit untuk menempel dan berkembang menjadi terumbu. Pola arah angin di Cagar Alam Krakatau dipengaruhi oleh angin barat yang bertiup dari arah Samudera Hindia dan membawa uap air yang menyebabkan musim penghujan pada bulan Januari hingga Juli. Sebaliknya angin timur bertiup dari Australia yang membawa angin kering dan menyebabkan musim kemarau, Angin ini bertiup pada Bulan Juli hingga Oktober. Pola angin inilah yang mempengaruhi pola arus di perairan ini.

Jika dilihat dari persen tutupan terumbu karang hidup adanya aktivitas vulkanik Gunung Anak Krakatau tidak sepenuhnya mempengaruhi kehidupan terumbu karang di perairan sekitar Cagar Alam Laut Kepulauan Krakatau. Titik sampling I yang terletak di sebelah timur Pulau Rakata dan berada di posisi yang terlindungi dari arus Samudera Hindia maupun arus dari Laut Jawa ternyata kondisi terumbu karangnya cukup baik meski berhadapan dengan Gunung Anak Krakatau.

\section{KESIMPULAN}

Berdasarkan hasil penelitian yang diperoleh dapat disimpulkan bahwa ditemukan 27 spesies terumbu karang yang termasuk dalam 7 famili, Acroporidae, Favidaei, Fungiidae, Ocullinidae, Pocilloporidae, Pectiniidae, dan Poritiidae, dan kondisi terumbu karang pada kedalaman 5 meter di titik I, dan II tergolong cukup baik, sedangkan kondisi terumbu karang pada kedalaman 5 meter di titik III dikategorikan dalam keadaan sedang.

\section{DAFTAR PUSTAKA}

Barnes, D. R. 1980. Invertebrate Zoology Fifth Edition. Sounders college. Philadelphia.

Boltovskoy, E. and R. Wright. 1976. Recent foraminifera. In: W. JUNK (ed.) Foraminifera. The Hague, Netherland.

Buzas, M. A. and S.J. culver. 1982. Biogeography of modern benthic foraminifera In :B. K. Sen Gupta (ed.) Modern Foraminifera. Univer-sity of Tennessee Studies in Geology 6: 90-106.

Chapman. F. 1902. The Foraminifera. An introduction to the study of the Protozoa. Longmans, Green and Co, London: $354 \mathrm{pp}$.

Dahl, A.L. 1981.Coral reef monitoring handbook. South Pacific Commis-sion Noumea, New Caledonia.
Hallock, P. 1981. Light dependence in Amphistegina. J. of Foraminifera Research 11 (1): 40-46.

Hallock, P; B.H. Lidz; E.M. Cockey-Burkhard and K.B. Donnelly. 2003. Foraminifera as bioindicators in coral reef assessment and monitoring the Foram Index Environmental Moni-toring and Assessment 81(3):221-238.

Kennedy, C. and Ziedler, W. 1976. The preparation of oriented thin sec-tions in micropaleontology: an improved method for revealing the internal morphology of foraminifera and other microfossils. Mycropa-leontology 22 (1): 104-107.

Natsir. 2010. Foraminifera Bentik Sebagai Indikator Kondisi Lingkungan Terumbu Karang Perairan Pulau Kotok Besar Dan Pulau Nirwana, Kepulauan Seribu. Pusat Penelitian Oseanografi-LIPI. Jakarta.

Nybakken, J.W. 1992. Biologi Laut : Suatu Pendekatan Ekologis. Alih Bahasa H. M. Eidma, Koesbiantoro, D. G. Benger, M. Hutomo, dan S. Sukarjo.Gramedia. Jakarta.

Nybakken, J.W. 1988. Biologi Laut : Suatu Pendekatan Ekologis. Alih Bahasa : H. M. Eidma, Koesbiantoro et el. Gramedia. Jakarta.

Putranto, S. 1997. Pengaruh Sedimntasi dan Limbah Terproduksi terhadap Komunitas Terumbu Karang Di Selat Sele, Serong-Irian Jaya. Institut Pertanian Bogor.

Suharsono. 1987. Pertumbuhan Karang. Oseano Vol IX No.2. Puslitbang Oseanologi-LIPI Jakarta.

Suharsono. 1996. Jenis-jenis Karang Yang Umum Dijumpai Di Perairan Indonesia. Puslitbang oseanologi-LIPI Jakarta.

Suharsono. 1998. Kesadaran masyarakat tentang terumbu karang (kerusakan di Indonesia). LIPI. Jakarta.

Soekarno. 1983. Kandungan zooxanthellae pada karang batu di terumbu karang pulau pari. Oseanologi di Indonesia.

Supriharyanto. 2000. Pelestarian dan pengelolaan sumberdaya alam di wilayah pesisir tropis. PT. Gramedia Pustaka Utama. Jakarta.

Timotius. 2003. Karakteristik terumbu karang. Makalah trining course. Yayasan terumbu karang indonesia.

Tomascik, T. A. J. Mah. K. Moosa. 1997. The Ecology Of The Indonesia Sea. . periplus edition.

UNEP. 1993. Monitoring Coral Reef For Global Change. Nairobi. United State Environment Program. 
Veron, J. E. N. 2000. Coral in space in time: the biography and evolution of the sclerentinia. AIMS. Corell university press. Ithaca and London.

Veron, J. E. N. 1988. Sclerentanian Of Eastern Australian. AIMS, Monogr. Ser, 4. Australian Gov, Pub Ser, Canberra. 422p.

Wallace, C.C. and Wolstenholme, J. 1999. Revision Of The Coral Genus Acropora (Sclerentina: Astrocoeniina: Acroporidae)
From Indonesia. Zool. J. Linnean Soc. 123: 199-384.

Wood, E.M. 1983. Reefs of the world. Biology and Guide. T.T.H. Publications, Inc.,LTD. Hongkong.

YAMANO, H; T. 2000. Importance of foraminifera for the formation and maintenance of a coral sand cay: Green Island, Australia. Coral Reefs (19) : 51-58. 